\title{
EARLY IDENTIFICATION OF THE STUDENT'S LEVEL IN THE TRANSVERSAL COMPETENCE “CREATIVITY, INNOVATION AND ENTREPRENEURSHIP"
}

\author{
Andrés Boza1, Llanos Cuenca1', M.M.E. Alemany², Faustino Alarcón², J.M. Prats- \\ Montalbán ${ }^{2}$ \\ ${ }^{1}$ Universitat Politècnica de València, School of Informatics (SPAIN) \\ ${ }^{2}$ Universitat Politècnica de València, School of Industrial Engineering (SPAIN)
}

\begin{abstract}
The initial level of a competence in our students is in many cases unknown for the teacher, when we talk about transversal competences. In addition, in some cases, they assume some skills to the students that can be wrong. The proposal developed in this paper focuses on identifying the student's initial level in the competence to adapt the teaching-learning process to the different levels found in our classroom. The proposal has been developed in the competence of creativity, innovation and entrepreneurship.
\end{abstract}

Keywords: Creativity, Innovation, Entrepreneurship, Teaching-Learning Process, Transversal Competences.

\section{INTRODUCTION}

Universities are redesigning their degrees or curricula according with new academic-professionals profiles. These new profiles require specific and transversal (or generic) competences, understood as "the set of knowledge, skills and attitudes to be able to mobilize a person, in an integrated manner to respond effectively to the demands of a given context" [1] . Specific competences belong to a specific area of knowledge (in a degree or master) and they are aimed at achieving a specific graduate profile. Transversal competences (also named generic competencies and transferable competencies) are generic and transferable in a wide variety of personal, social, academic and professional contexts throughout life [2].

The initial level of competence in a student related to the non-transversals competences can be identified through the structure of the previous studies that has been attended. In this way, the teacher has a guide or reference, about what to teach in depth and amplitude. However with regards to transversal competences, the initial level achieved by the students is not easy to determine, and most teachers act in the same way in both cases.

When a teacher starts his or her activity in a new group of students, the skills of these students about effective communication, critical thinking or teamwork (among others) are unknown to the teacher, but in some cases they assume that the students have a determined level for each competence and they develop activities according to these "supposed" level.

Our expertise acquired in the previous innovation projects has left in evidence that, activities with a specific purpose that we develop in our classes, can give us contrary results or achieve different impact into the students. Students have different ways of coping an activity or a challenge. Sometimes the same activity can result bored for some students, but at the same time, very tough and challenging for other students.

The transversal competence "creativity, innovation and entrepreneurship" is not out of this problem, when the activities developed in class do not take into account the student's needs in particular. This competence belong to the project "Transversal UPV competences" launched by the Universitat Politècnica de València which promotes the acquisition of these competencies among our students. This project includes 13 generic competences [3]. 
The proposal developed in this paper focus on identifying the student's initial level in the competence to adapt the teaching-learning process to the different levels found in our classroom.

The paper is organized as follow, section two describes the objective, section three includes procedure to identify the student's level in the transversal competence and finally section four presents the conclusions.

\section{OBJECTIVES}

The general objective consists of identifying the students according to different levels in the competence "creativity, innovation and entrepreneurship", with the aim of defining different roadmaps that allow to improve their properly achievement of this competence.

In a more concrete way, the detailed objectives to accomplish are:

1 Designing a scale to identify levels of achievement of the competence.

2 Designing initial activities to pre-assessment creativity, innovation and entrepreneurship competences for each student.

3 Assessing the initial level of each student in the transversal competence (through the activities designed in the objective 2).

4 Identify the level of each student in the transversal competence.

\section{IDENTIFICATION OF THE STUDENT'S LEVEL IN THE TRANSVERSAL COMPETENCE "CREATIVITY, INNOVATION AND ENTREPRENEURSHIP"}

\subsection{Designing a scale to identify levels of achievement of the competence}

The design of the scale is justified by the requirement to measure the level at which the learning activity contributes to the coverage of the competence. Measurement means assigning numbers, symbols or values to the properties of objects or events according to specific rules [4]. In social sciences, researchers work with abstract concepts that cannot be characterized as objects or events. In this field measurement can be defined as the process of linking abstract concepts with empirical indicators, which is carried out by means of an explicit and organized plan to classify (and often quantify) the available data (the indicators), in terms of the concept that the researcher has in mind [5], in our case to identify levels of achievement of the competence. According to Grinnel and Unrau [6] the function of measurement is to match the "real world" with the "conceptual world". The first provides empirical evidences while the second provides theoretical models to understand that segment of the real world we are trying to describe.

The data measuring instrument plays a central role in this process. Without it there are no classified observations. Thus, the measuring instrument records represent visible values of abstract concepts. Although there is no perfect measurement, the idea is to get as close as possible to a faithful representation of the variables to be observed using the measuring instrument [6].

There are three basic issues regarding the variables to be considered when constructing an instrument [7]: operationalization, codification and the establishment of measurement levels:

1 The technical term "operationalization of variables" is used in research to designate the process by which the variable is transformed from abstract concepts to concrete, observable and measurable terms, i. e., dimensions and indicators [8]. This process includes the stages of nominal and conceptual definition of the variable, the dimensionalization of the variable (determining its factors, dimensions or components), defining indicators for the dimensions and finally identifying, developing or generating items or values for each indicator.

2 Data encoding means assigning to the data a numeric value or symbol that represents it. In other words, numeric values or signs that have a meaning are assigned to the different categories (response options) of each item or variable. For example, the Male - Female category can be coded as $1-2$, or the item "In this company I am free to make decisions" can be coded as 5) I totally agree; 4) All right; 3). Neither agree nor disagree; 2) Disagree; 1) Strongly disagree. 
3 The best-known measurement levels are: (i) Nominal measurement level, where there are two or more categories of the item or variable, and there is no intrinsic ordering or hierarchy to the categories (e. g. gender is a categorical variable having two categories: male and female); (ii) Ordinal measurement level, where there are several categories that maintain a clear higher to lower ordering (e. g. president is more than vice-president, and in turn, more than general manager, but it is not possible to specify how much more); (iii) Interval measurement level. In addition to the ordering or hierarchy between categories, equal interchanges are established in the measurement, i. e., the distances between categories are the same across the entire scale (e. g. the variable of the number of employees in charge).

In transversal competences, the scale design is a complex process that depends on the approach of the teacher (as designer of the scale) concerning the analysis of the transversal competence and on the nature of the competence itself. For example, the transversal competence "Lifelong Learning" has very different dimensions from the competence "Effective Communication", both because of the intrinsic characteristics of the competences and because of the subjective concerns of the teacher when defining dimensions and indicators.

In the case of the UPV transversal competence "Innovation, Creativity and Entrepreneurship" the competence is approached as a process. Specifically, taking the descriptors of the definitions of innovation, creativity and entrepreneurship competence is defined as a process to be followed, it contains the following steps [2] :

1 Environmental analysis (opportunities);

2 Proposal of creative ideas (generate ideas);

3 Deployment (execution);

4 Risk and benefit assessment (added value).

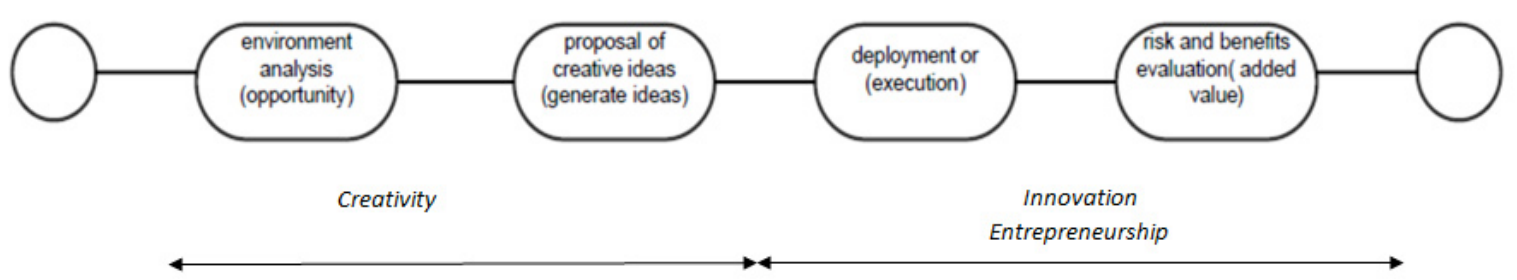

Figure 1: Process related to the competence of Innovation, Creativity and Entrepreneurship [2].

Thus, the operationalization of the competence in dimensions, indicators and items is presented in the following table:

Table 1. Operationalization of the competence of Innovation, Creativity and Entrepreneurship.

\begin{tabular}{|c|c|c|c|}
\hline Variable & Dimension & Indicator & Item \\
\hline \multirow{4}{*}{$\begin{array}{l}\text { Transversal Competence of } \\
\text { Innovation, Creativity and } \\
\text { Entrepreneurship }\end{array}$} & $\begin{array}{l}\text { Environmental analysis } \\
\text { (opportunities) }\end{array}$ & $\begin{array}{l}\text { The student questions } \\
\text { reality. }\end{array}$ & \multirow{4}{*}{$\begin{array}{l}\text { Categories: } \\
\text { D. Not achieved } \\
\text { C. Under } \\
\text { development } \\
\text { B. Good / suitable } \\
\text { A. Excellent / } \\
\text { exemplary }\end{array}$} \\
\hline & $\begin{array}{l}\text { Proposal of creative ideas } \\
\text { (generate ideas) }\end{array}$ & $\begin{array}{l}\text { The student contributes } \\
\text { ideas. }\end{array}$ & \\
\hline & Implementation (execution) & $\begin{array}{l}\text { The student formally } \\
\text { shapes the ideas. }\end{array}$ & \\
\hline & $\begin{array}{l}\text { Risk and benefit assessment } \\
\text { (added value) }\end{array}$ & $\begin{array}{l}\text { The student identifies } \\
\text { results. }\end{array}$ & \\
\hline
\end{tabular}

The table 1 should be understood as one of the ways to perform the operationalization of the competence, since as indicated above, the designers of each scale are conditioned by the nature of each transversal competence, and their own perspective. Thus, for other scales, measurements from 0 to 10 may be required, using Likert scales or using semantic differentials (eg, the student is very creative --- the student is not very creative). 
Regarding the levels of measurement, in our case (identification of the student's level in the transversal competence "creativity, innovation and entrepreneurship") at least two levels are required. The approach followed by this proposal is to establish the levels as an orderly path for the scope of the competence, so that the levels to be used are the ordinal measurement level or the interval measurement level.

The proposal developed in this paper focuses on identifying the student's initial level in the competence to adapt the teaching-learning process to the different levels found in our classroom. This is the reason why the ordered scale is required. However, for other proposals you can also use the nominal measurement level when you want to focus on the dimensions themselves and not so much in their evolution (eg "The activity addresses" Categories: Innovation / Creativity / Entrepreneurship).

\subsection{Designing initial activities to pre-assessment creativity, innovation and entrepreneurship competences for each student}

The design of an activity or activities for early identification of the student's level in the transversal competence "creativity, innovation and entrepreneurship" is a challenge due to the complexity of the competence, including related elements that can be addressed independently.

Thus, we could design an activity that addresses globally the three elements that make up the competence "Creativity, Innovation and Entrepreneurship", or design separate activities for the evaluation of each of these components.

It is important to keep in mind that the purpose of the activity is not to serve as a learning tool for the student, but to be useful as a tool for measuring the initial level of competence in the student.

In the search of these activities we can find widely used proposals such as the Torrance test of creative thinking [9] and in turn, criticism of these same proposals as Piffer [10] that questions that the Torrance test deals with creative thinking, since it puts the focus on divergent thinking, leaving aside aspects that are also important for creativity, such as convergent thinking. This complexity arises in the same way if we talk about innovation or entrepreneurship.

\subsection{Assessing the initial level of each student in the transversal competence}

The activities proposed in the previous step pursue early identification of the student's level in the transversal competence "creativity, innovation and entrepreneurship". In this step, the deployment of these activities in the classroom to carry out the evaluation is pursued.

For this deployment, two important aspects must be considered:

1 Early identification. From the temporary point of view, the activity must be carried out in the first sessions of the subject. Thus, the teacher can react and act according to the results.

2 Student's level. From an individual or group perspective, the activity must be done individually and be able to know the results individually to offer personalized proposals to each student.

\subsection{Identify the level of each student in the transversal competence}

As a result of the previous evaluation, we can identify the level of each student in the transversal competence. This allows make groups of the students with common levels to be able to act in a customized way depending on the level in the competence.

An example can be seen in more detail in the following graphic where you work with a group of 50 students and a scale 0 out to 10 is used regarding the initial level of the student in the competence. Each point represents a student: 


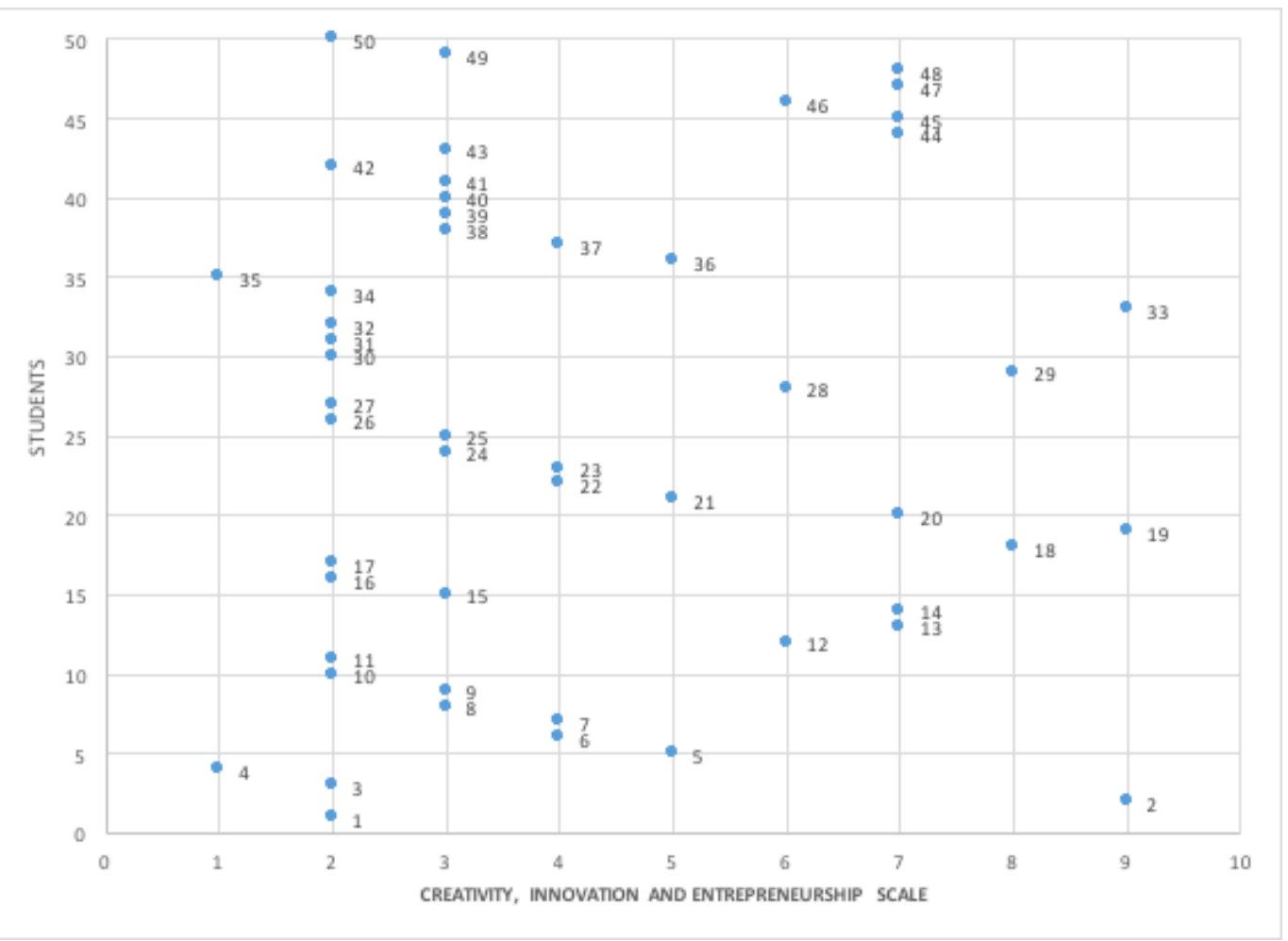

Figure 2 Level of competence for each student.

The graphic represents the dispersion diagram of the results obtained. For this example, the creative, innovation and entrepreneurship capacity of students 33, 19 and 2 differs a lot from that of students 35 and 4 ; hence, the activities for the development of the competence to be carried out in these two groups of students should be different. Thus, groups of students for the development of activities should be established according to their capacity and initial potential.

\section{CONCLUSION}

The problem of approaching the particular needs of each student at the time of facing and developing the competence "creativity, innovation and entrepreneurship" has been addressed through the early identification of the student's level in the transversal competence.

The stages addressed for this purpose i) designing a scale to identify levels of achievement of the competence, ii) designing initial activities to pre-assessment creativity, innovation and entrepreneurship competences for each student. iii) assessing the initial level of each student in the transversal competence. iv) identify the level of each student in the transversal competence) allow adapt the teaching-learning process to the different levels found in our classroom.

The early identification of the student's level in the transversal competence enables:

1 To have a broad vision of the students in our classroom about the starting point at the competence.

2 To identify clusters of students at the same level regarding the competence.

3 To adapt the teaching-learning process according with these clusters.

Thus, this proposal incorporates the student as a key element in the teaching-learning process.

\section{ACKNOWLEDGEMENTS}

This research has been carried out under the project of innovation and educational improvement (PIME 2017-18 Ref. A10) funded by the Universitat Politècnica de València and the School of Informatics. 


\section{REFERENCES}

[1] P. Perrenoud, "Diez nuevas competencias para enseñar," Tiempo Educ., vol. 9, no. 17, p. 159, 2008.

[2] A. Boza, M. Fernández-Diego, L. Ruiz, M. Gordo, M. M. E. Alemany, F. Alarcón, and L. Cuenca, "Transversal Competences as a Medium of Teaching. The Case of Creativity, Innovation and Entrepreneurship," in Strategic Innovative Marketing, Springer, 2017, pp. 3-10.

[3] Universitat Politècnica de Valencia, "Competencias Transversales UPV." [Online]. Available: http://www.upv.es/contenidos/COMPTRAN/. [Accessed: 01-Jul-2017].

[4] S. S. Stevens, "Mathematics, measurement, and psychophysics," in Handbook of Experimental Psychology, no. 1, 1951, pp. 1-49.

[5] E. G. Carmines and R. A. Zeller, "Reliability and validity assessment," Quantitative Applications in the Social Sciences, vol. 17. p. 70 p., 1979.

[6] R. M. Grinnell Jr and Y. Unrau, Social work research and evaluation: Quantitative and qualitative approaches. Cengage Learning, 2005.

[7] R. Hernandez Sampieri, C. Fernandez Collado, and M. del P. Baptista Lucio, Metodología de la investigación. 2014.

[8] F. Arias, "El proyecto de investigación," Introducción a la metodología científica. 2006.

[9] E. Torrance, "The Torrance test of creative thinking: Norms-technical manual. Bensenville, Illinois: Scholastic Testing Services." Inc, 1974.

[10] D. Piffer, "Can creativity be measured? An attempt to clarify the notion of creativity and general directions for future research," Think. Ski. Creat., vol. 7, no. 3, pp. 258-264, 2012. 